\title{
Dynamic regulation of the angiotensinogen gene by DNA methylation, which is influenced by various stimuli experienced in daily life
}

\author{
Masashi Demura $^{1}$, Yosiki Demura ${ }^{2}$, Yoshiyu Takeda ${ }^{3}$ and Kiyofumi Saijoh ${ }^{1}$
}

Angiotensinogen (AGT) has a central role in maintaining blood pressure and fluid balance. DNA methylation is an epigenomic modification maintaining a steady pattern in somatic cells. Herein we summarize the link between AGT regulation and DNA methylation. DNA methylation negatively regulates AGT expression and dynamically changes in response to continuous AGT promoter stimulation. High-salt intake and excess circulating aldosterone cause DNA demethylation around the CCAAT enhancerbinding protein-binding sites, thereby converting the phenotype of $A G T$ expression from an inactive to an active state in visceral adipose tissue. Salt-dependent hypertension may be partially affected by increased adipose AGT expression. Because angiotensin II is a well-established aldosterone-releasing hormone, stimulation of adipose AGT by aldosterone creates a positive feedback loop. This effect is pathologically associated with obesity-related hypertension, although it would be physiologically favorable for humans to efficiently retain their body fluid. The clear difference in DNA demethylation patterns between aldosterone and cortisol indicates a difference in the respective target DNA-binding sites between mineralocorticoid and glucocorticoid receptors in the $A G T$ promoter. Stimulation-induced interactions between transcription factors and target DNA-binding sites trigger DNA demethylation. Dynamic changes in DNA methylation occur in relaxed chromatin regions both where transcription factors actively interact and where transcription is initiated. In contrast to rapid histone modifications, DNA demethylation and remethylation will progress relatively slowly over days or years. A wide variety of stimuli in daily life will continue to slowly and dynamically change DNA methylation patterns throughout life. Wise choices of beneficial stimuli will improve health.

Hypertension Research (2015) 38, 519-527; doi:10.1038/hr.2015.42; published online 26 March 2015

Keywords: angiotensinogen; corticosteroid; DNA demethylation; DNA remethylation; visceral adipose tissue.

\section{INTRODUCTION}

DNA methylation is a stable, long-term epigenetic modification that affects gene expression without altering its DNA sequence. In mammals, DNA methylation is a covalent modification that occurs primarily at position 5 on cytosine rings within CpG dinucleotides that usually represses gene transcription. Additionally, DNA hypermethylation in gene promoter regions generally silences genes. Thus DNA methylation has a central role in the development and differentiation of mammalian cells. A logical connection between carcinogenesis and DNA methylation has been well established. Somatic changes and dysregulation of DNA methylation have recently been demonstrated to be involved in the development of hypertension. ${ }^{1}$

It is hypothesized that once DNA methylation patterns are established during cellular development, differentiation and disease progression, they are stably maintained. However, recent progress in this field has revealed DNA methylation pattern dynamics in response to various environmental stimuli. Daily factors involved in the alteration of DNA methylation include chemicals, ${ }^{2}$ infection, ${ }^{3}$ smoking, ${ }^{4,5}$ exercise ${ }^{6}$ and learning. ${ }^{7}$ Even climate could be involved in changes in DNA methylation. ${ }^{8}$ Lifestyle influences metabolism via DNA methylation. ${ }^{9}$ These observations imply an association between DNA methylation dynamics and multifactorial lifestyle-related diseases, such as hypertension, diabetes mellitus and dyslipidemia.

Angiotensinogen (AGT) is a precursor of angiotensin and is a part of the renin-angiotensin-aldosterone system (RAAS) that regulates blood pressure, body fluids and electrolyte homeostasis. The liver is the major source of circulating AGT, which is secreted into the bloodstream. ${ }^{10}$ There is growing evidence suggesting that, in addition to hepatic AGT, adipose AGT has a potent role in the development of hypertension. ${ }^{11-16}$

The association between hypertension and obesity is well established. In humans, adipose $A G T$ expression is increased in obese individuals, ${ }^{14}$ and circulating AGT levels are elevated in obese patients with hypertension. ${ }^{17}$ In mice, adipose AGT contributes to circulating AGT levels, ${ }^{11}$ and adipocyte-specific AGT deficiency decreases plasma AGT concentrations and prevents obesity-induced hypertension. ${ }^{15,16}$

${ }^{1}$ Department of Hygiene, Graduate School of Medical Science, Kanazawa University, Kanazawa, Japan; ${ }^{2}$ Department of Respiratory Medicine, Fukui Red Cross Hospital, Fukui, Japan and ${ }^{3}$ Division of Endocrinology and Hypertension, Graduate School of Medical Science, Kanazawa University, Kanazawa, Japan

Correspondence: Dr M Demura, Department of Hygiene, Graduate School of Medical Science, Kanazawa University, Kanazawa 920-8640, Japan.

E-mail: m-demura@med.kanazawa-u.ac.jp

Received 6 December 2014; revised 28 January 2015; accepted 3 February 2015; published online 26 March 2015 
Hypertension can lead to atherosclerosis in association with increased oxidative stress. ${ }^{18}$ Multiple risk factors, including genetic factors, ${ }^{19}$ contribute to the pathogenesis of hypertension, and genetic variants of the RAAS have been implicated in the risk of developing hypertension. ${ }^{20}$ Over the years, many studies, including RNA-induced epigenetic silencing, ${ }^{21}$ have been performed to study AGT expression regulation. However, the role of DNA methylation in AGT regulation has remained unclear until recently. Here this review focuses on recent advances in the understanding of the regulation of adipose $A G T$ in relation to DNA methylation. We discuss factors affecting DNA methylation dynamics as well as where and how these changes occur.

\section{CONTRIBUTION OF DNA METHYLATION TO HUMAN AGT GENE TRANSCRIPTION}

DNA methylation is generally involved in stabilizing the silent state of genes either by blocking DNA-binding transcription factors or by recruiting methyl-CpG-binding domain (MBD) proteins, which favor the formation of the transcriptionally inactive forms of chromatin (heterochromatin). Among MBD proteins, MECP2, MBD1 and MBD2 repress the transcription of methylated gene promoters. ${ }^{22}$

The human AGT promoter possesses a number of CpG dinucleotides that are targets for DNA methylation (Figure 1). Located near a CCAAT enhancer-binding protein (CEBP)-binding site that contains a CpG dinucleotide at positions - 218/-217, the human AGT promoter is hypomethylated in tissues and cells with high AGT expression (liver, heart and HepG2 hepatocytes) but not in those with low expression (adrenal glands, leukocytes and adrenocortical H295R cells). ${ }^{23}$ Thus the methylation status of a CPG dinucleotide within the CEBP-binding site appears to be inversely associated with AGT expression. DNA sequences upstream of the $A G T$ gene cloned into the luciferase plasmid depend upon DNA methylation. DNA methylation represses the transcriptional activity of those sequences. ${ }^{23}$
In the human $A G T$ promoter, USF1/ESR $1,{ }^{24,25} \mathrm{CEBPB} / \mathrm{NR} 3 \mathrm{C} 1,{ }^{26}$ hepatocyte nuclear factor 1 homeobox A (HNF1A) ${ }^{27}$ and HNF4A/ $\mathrm{NR} 2 \mathrm{~F}^{28}$ interact with DNA sequences containing $\mathrm{CpG}$ dinucleotides at positions $-18 /-17,-218 /-217,-245 /-244$ and $-261 /-260$, respectively (Figure 1). All of these transcription factors function as activators of $A G T$ gene transcription except NR2F1 in human hepatocytes. NR2F1 represses $A G T$ gene transcription. ${ }^{28}$ Among these binding sequences containing $\mathrm{CpG}$ dinucleotides, polymorphisms exist at positions $-20(\mathrm{~A} / \mathrm{C}, \mathrm{rs5050})$ and -217 (A/G, rs5049), indicating their influence on DNA-protein interactions. Specifically, $-217 \mathrm{G}$ creates a CpG dinucleotide (positions -218/-217), whereas the CpG dinucleotide disappears with $-217 \mathrm{~A}$, demonstrating the direct impact of DNA methylation on $\mathrm{CEBPB} / \mathrm{NR} 3 \mathrm{C} 1$ binding to the target DNA site at position $-217 \mathrm{C}$.

DNA methylation tends to impair USF1 binding with either A or C at position -20 in nuclear proteins from the adrenocortical H295R and hepatic HepG2 cell lines. ${ }^{23}$ DNA methylation also tends to inhibit ESR1 binding in H295R cells. There is no other obvious difference in ESR1 binding between $-20 \mathrm{~A}$ and $-20 \mathrm{C}$ irrespective of the DNA methylation status in H295R cells and HepG2 cells.

Contrary to expectations, the $-217 \mathrm{~A} / \mathrm{G}$ polymorphism and DNA methylation at position -217 have little effect on CEBPB binding in H295R and HepG2 cells. NR3C1 recruitment and glucocorticoidinduced $A G T$ gene promoter activity in the context of-217A are superior to $-217 \mathrm{G}$ in Hep3B cells. ${ }^{26}$ Similarly, NR3C1 binding to $-217 \mathrm{~A}$ is 2.5 -fold greater than $-217 \mathrm{G}$ in HepG2 cells. ${ }^{23}$ DNA methylation at position -217 tends to increase rather than decrease NR3C1 binding in HepG2 cells. Neither the $-217 \mathrm{~A} / \mathrm{G}$ polymorphism nor DNA methylation at position -217 affects NR3C1 binding in H295R cells, suggesting that the target proteins and cell types make a difference in the respective effects of the $-217 \mathrm{~A} / \mathrm{G}$ polymorphism and DNA methylation on DNA-protein interactions.

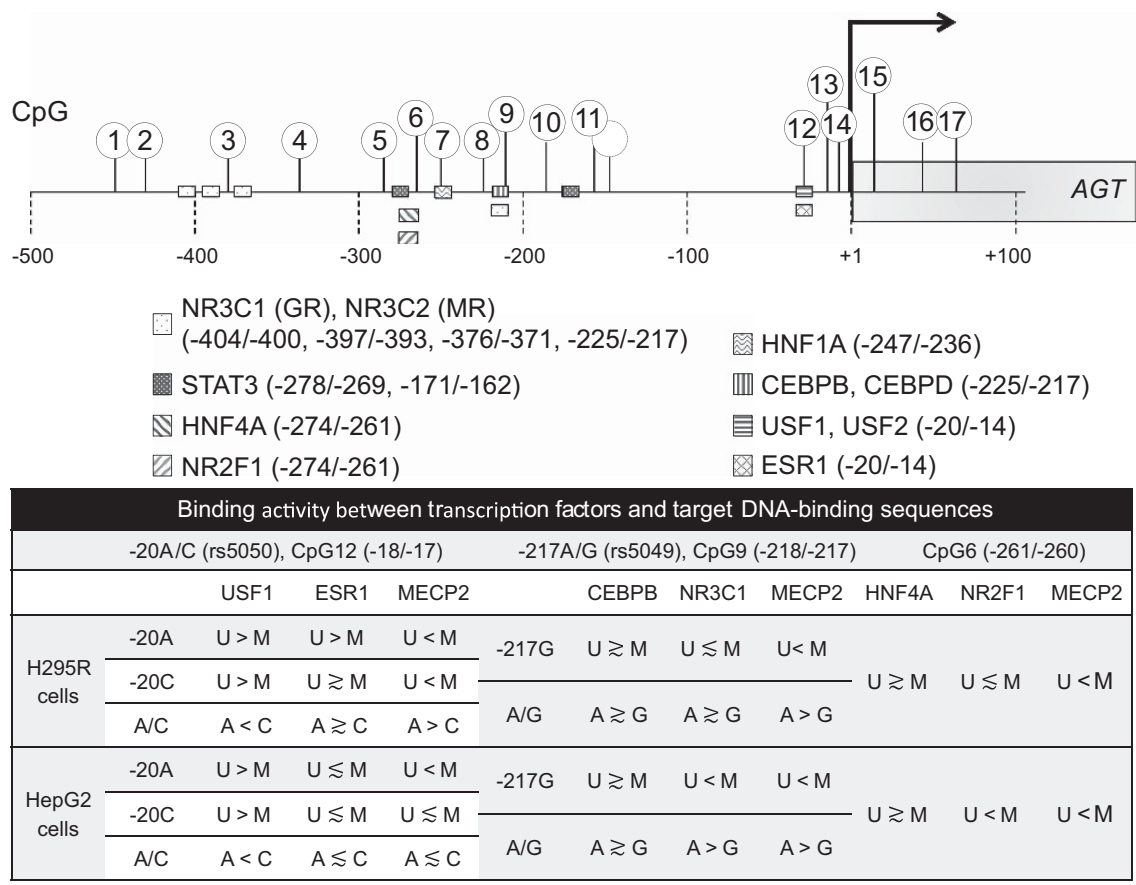

Figure $1 \mathrm{CpG}$ dinucleotides and transcription factor-binding sites in the $A G T$ promoter. Nucleotide numbers are relative to the transcription start site. CpG dinucleotides from -483 to +78 are numbered from the $5^{\prime}$ to $3^{\prime}$ ends. A CpG dinucleotide denoted as an unnumbered lollipop was not analyzed in the previous study. ${ }^{23} \mathrm{GR}$, glucocorticoid receptor; M, methylated CpG; MR, mineralocorticoid receptor; U, unmethylated CpG. A full color version of this figure is available at the Hypertension Research journal online. 
a

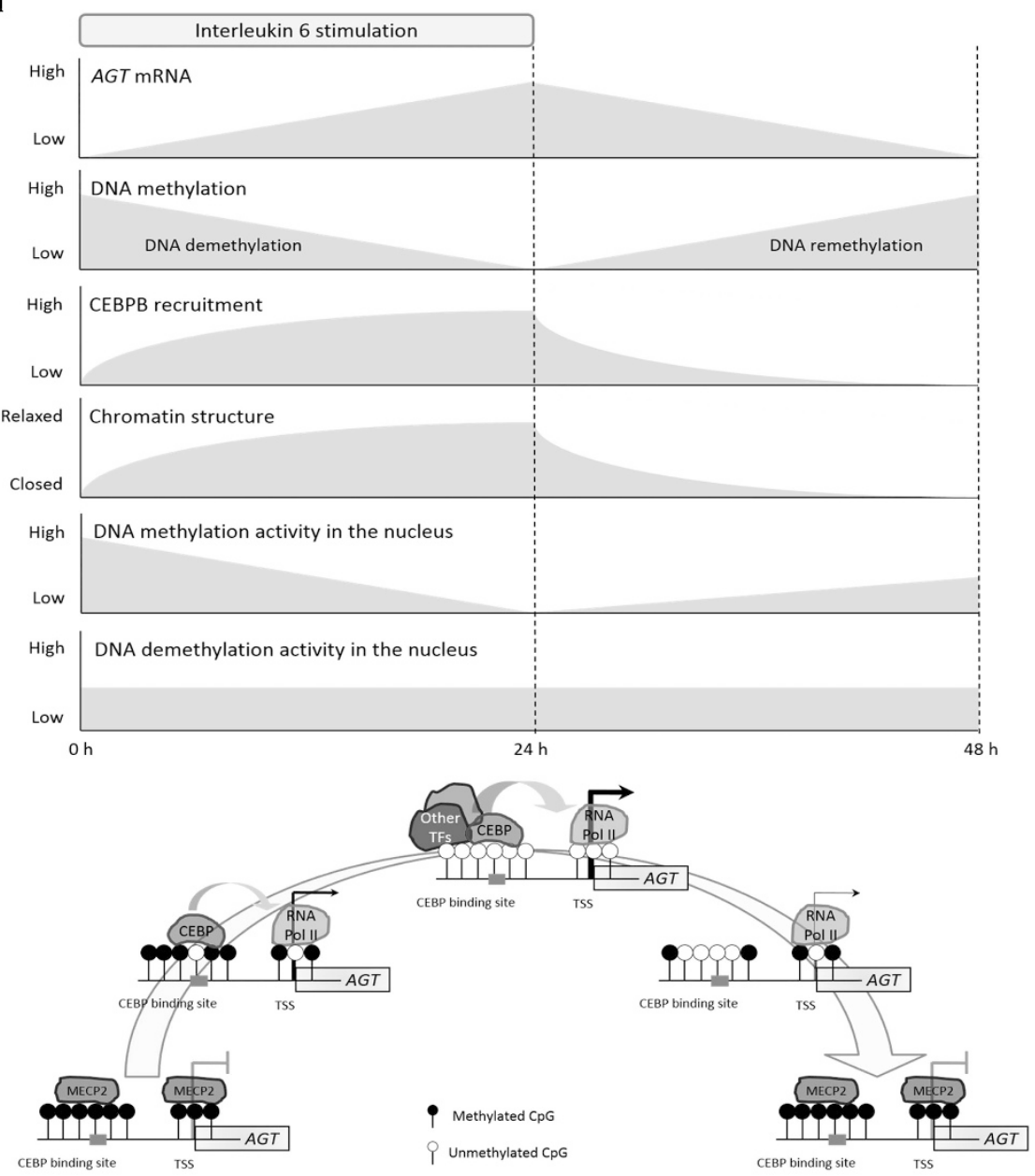

b

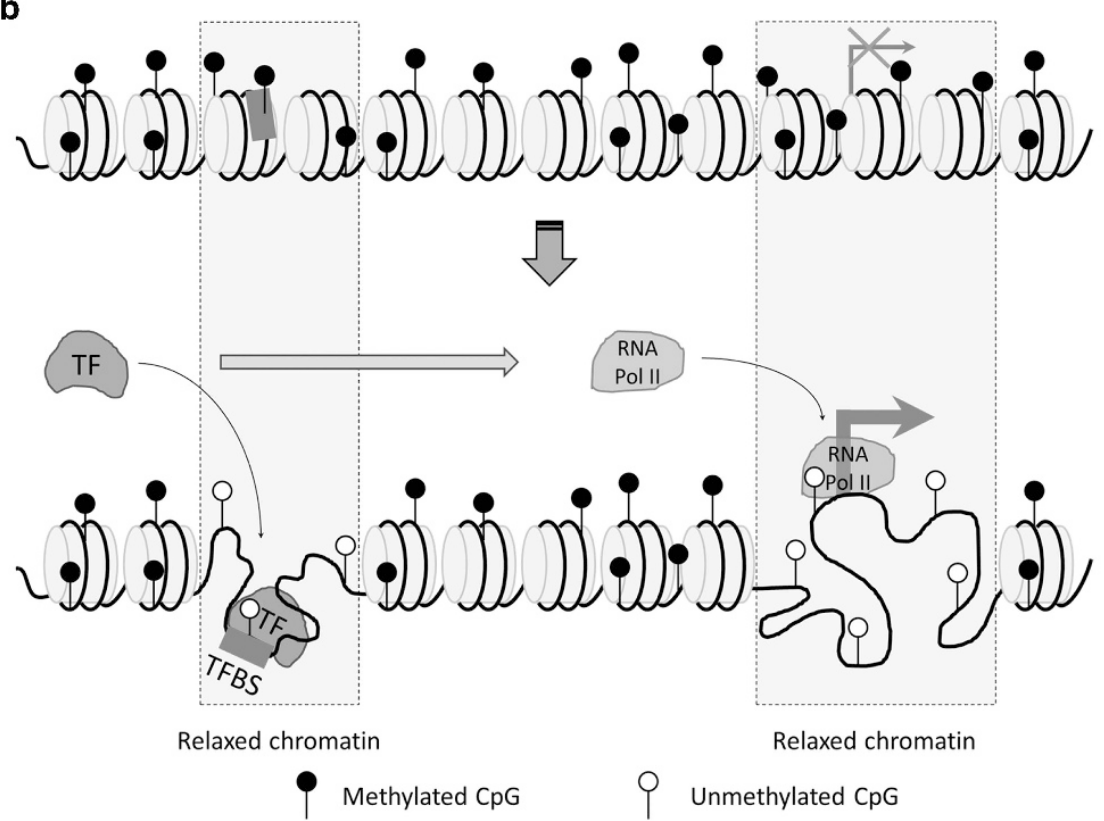

Figure 2 (a) Dynamics of AGT promoter DNA demethylation and remethylation following interleukin 6 stimulation. (b) Chromatin regions where DNA demethylation takes place. CEBP, CCAAT/enhancer binding protein; RNA pol II, RNA polymerase II; TF, transcription factor; TFBS, transcription factorbinding site; TSS, transcription start site. A full color version of this figure is available at the Hypertension Research journal online. 
DNA methylation affects HNF4A binding by $<10 \%$ in nuclear proteins from H295R and HepG2 cell lines. By contrast, DNA methylation tends to increase rather than decrease NR2F1 binding in HepG2 cells. This is consistent with the inhibitory effect of NR2F1 on AGT transcription in HepG2 cells.

DNA methylation also tends to increase MECP2 binding at positions $-18 /-17,-218 /-217$ and $-261 /-260$. MECP2 binding to the AGT promoter in $\mathrm{H} 295 \mathrm{R}$ cells is threefold to fivefold higher than in HepG2 cells, consistent with the lower level of AGT expression associated with DNA promoter hypermethylation in H295R cells compared with HepG2 cells. $^{23}$ MECP2 competes against positive transcription factors for target DNA sites in the AGT promoter. For example, competitiveness between MECP2 and transcription factors, including CEBPB and NR3C1, occurs at positions -218 / - 217 of the $A G T$ promoter. The predominant recruitment of MECP2 over positive transcription factors promotes low AGT expression in H295R cells, and the opposite occurs in HepG2 cells.

In conclusion, DNA methylation tends to impair the interaction between some transcription factors and their target DNA sites, whereas it tends to facilitate the interaction between MECP2 and CpG dinucleotides in the $A G T$ promoter (summarized in Figure 1).

\section{DNA DEMETHYLATION AND REMETHYLATION DYNAMICS IN THE HUMAN AGT PROMOTER}

DNA methylation patterns are generally thought to stabilize after development and differentiation. However, growing evidence suggests that various environmental factors in daily life can induce changes in DNA methylation in somatic tissues. ${ }^{2-9,23}$ Although DNA demethylation almost always causes transcriptional activation, it is a consequence rather than a cause of transcriptional activation. ${ }^{23,29-33}$

Cytosines of $\mathrm{CpG}$ dinucleotides are either methylated or unmethylated at the cellular level. Promoter DNA methylation is generally associated with transcriptional silencing or decreased gene expression. Thus the number of cells with an unmethylated promoter determines the corresponding gene expression level in a tissue. Because of their powerful impact on transcriptional activity, tissue DNA methylation patterns are of physiological importance to human health, thereby influencing constitution. In this context, it is very important to understand the dynamics of DNA demethylation and remethylation upon stimulation and cessation of transcriptional activation.

Overall, 17 out of the $18 \mathrm{CpG}$ dinucleotides within the human AGT promoter and its first exon $(-459$ to +66$)$ have been analyzed to determine where and how DNA demethylation and remethylation affects interleukin 6 (IL6) stimulation. Instead of using hepatoma HepG2 cells with a completely demethylated AGT promoter, H295R cells with an incompletely demethylated promoter were employed to determine DNA demethylation dynamics. DNA demethylation was detected within $12 \mathrm{~h}$ of IL6 stimulation and reached a maximum level $24 \mathrm{~h}$ following stimulation. The first DNA demethylation event occurred around a CEBP-binding site (positions $-225 /-217)^{26,34}$ as well as a transcription start site (TSS); DNA demethylation from CpG9 (positions $-218 /-217$ ) to CpG12 (positions - 18/-17) had started by that time, spreading out and stretching to CpG2 (positions - 434/ -433 ) on the $5^{\prime}$-upstream side and to CpG17 (positions $+65 /+66$ ) on the $3^{\prime}$-downstream side during IL6 stimulation ${ }^{23}$ (Figures 1 and 2a).

Once established, DNA methylation patterns tend to be maintained. Two independent research groups have elegantly offered valuable insight into DNA methylation pattern stability and maintenance. They described that transcriptional activation by estrogen induces cyclical DNA demethylation and remethylation of promoters and the first exons of several estrogen-responsive genes. ${ }^{31,32}$ During estrogen stimulation, the DNA repair system demethylates DNA by replacing a methylated with an unmethylated cytosine in cells, whereas DNA methyltransferase 1 (DNMT1), DNMT3A and DNMT3B methylate DNA. $^{32}$ The periodic time interval of DNA demethylation and remethylation is approximately $20-40 \mathrm{~min}$. Therefore, although other factors such as histone modification ${ }^{35}$ can influence changes in DNA methylation, the stability and maintenance of DNA methylation patterns appear to be due to the competition between the DNA repair system and DNMT enzymes. Periodic DNA demethylation and remethylation in the AGT promoter following IL6 stimulation has not been observed in the analyses of DNA methylation patterns every $6 \mathrm{~h} .{ }^{23}$ However, more frequent analyses of DNA methylation patterns such as every $10 \mathrm{~min}$ would demonstrate gradual AGT promoter hypomethylation with periodic DNA demethylation and remethylation cycles lasting for tens of minutes.

$\mathrm{CEBPB}^{26,34}$ or $\mathrm{CEBPD}^{26}$ overexpression enhances the IL6-induced AGT transcription in human hepatocytes. Along with this observation, IL6 stimulation recruits CEBPB into its target DNA-binding site (positions -225/-217). The high level of CEBPB recruitment increases with DNA demethylation progression around the CEBPbinding site (positions $-225 /-217$ ), which proceeds simultaneously with chromatin relaxation. ${ }^{23}$ The IL6-induced interaction between CEBPB and its binding site (positions -225/-217) triggers DNA demethylation around that site. DNA demethylation occurs in relaxed chromatin regions both at sites of CEBPB interaction and transcriptional initiation. ${ }^{23}$

Local DNA demethylation is one of several steps in the serial recruitment of multiple transcription factors. ${ }^{29}$ In addition to CEBP, signal transducer and activation transcription factor 3 (STAT3) and HNF1A are involved in IL6-induced AGT transcription in human hepatocytes. The positive effect of STAT3 on IL6-induced AGT transcription is mediated by its interaction with its two target DNA sites (positions $-278 /-269^{\text {ref. }} 36$ and positions $-171 /-162$ ). ${ }^{27,36}$ IL6 also induces the interaction between HNF1A and the AGT promoter at positions $-247 /-236 .{ }^{27}$ Additional transcription factors such as STAT3 and HNF1A are recruited when chromatin is relaxed and DNA is unmethylated, as $\mathrm{MBD}$ proteins have difficulty interacting with DNA without methylated CpG dinucleotides. DNA demethylation on the 5'-upstream side reaches CpG2 (position -434/-433), suggesting that as-yet-unidentified DNA-binding transcription factors are also involved in IL6-induced AGT transcription. Following IL6 withdrawal, DNA remethylation concurrently progresses in a reverse manner over the next $24 \mathrm{~h}^{23}$ (Figure 2a).

Similar changes in DNA demethylation and remethylation have also been observed in the CYP11B2 (aldosterone synthase gene) promoter. Transcriptional activation by potassium gradually causes DNA demethylation around CREB1- and NR4A-binding sites as well as a TSS over 7 days, and its withdrawal reverses this process over the next 7 days in H295R cells. Although the CYP11B2 promoter is a non-CpG island promoter, each of the CREB1- and NR4A-binding sites (at positions $-71 /-64$ and positions $-129 /-114$, respectively) contains one $\mathrm{CpG}$ dinucleotide, and these binding sites are crucial for basal transcription activity. In addition, two CpG dinucleotides (positions $+37 /+38,+45 /+46)$ are located near the TSS. This CpG content of the CYP11B2 promoter offers a much greater opportunity to precisely analyze the association between DNA methylation pattern dynamics, transcription factor recruitment and chromatin relaxation than the AGT promoter. As is the case with the AGT promoter, DNA demethylation occurs upon stimulation, whereas remethylation occurs when the stimulus is removed within the CYP11B2 promoter. DNA demethylation at the CREB1-binding site has been detected within 
2 days of stimulation. Changes in DNA demethylation at the NR4Abinding site and around the TSS occur 2 days later than those at the CREB1-binding site. The NR4A-binding site, its TSS and the CREB1binding site were remethylated to pretreatment levels 2, 4 and 7 days following the end of stimulation, respectively. These changes in DNA methylation patterns are linked to both chromatin relaxation as well as the abundance of transcription factor interactions (unpublished results). Collectively, dynamic changes in DNA methylation following stimulation occur in relaxed chromatin regions, both where transcription factors actively interact and where transcription is initiated (Figure 2b).

DNA demethylation is mediated by the interaction between DNAbinding transcription factors and factors involved in DNA demethylation, that is, the DNA repair system. ${ }^{32}$ DNA remethylation is mediated by locally recruited DNMTs. ${ }^{32}$ The nearby binding of MECP2 with methylated $\mathrm{CpG}$ dinucleotides facilitates local DNMT recruitment, thereby assisting DNA remethylation. ${ }^{32}$ Thus the recruitment of factors involved in DNA methylation in a manner dependent on transcription factor-binding sites and methylated CpG dinucleotides is of great importance to local DNA methylation dynamics. A balance between DNA methylation and demethylation activities in the nucleus also has a role in changes in DNA methylation patterns. DNA methylation activity gradually decreases during IL6 stimulation in H295R cells ${ }^{23}$ (Figure 2a). Similarly, high-salt intake decreases DNA methylation activity in rat adipose tissue. ${ }^{23}$ Therefore, decreased DNA methylation activity may contribute to DNA demethylation under both conditions. However, the contribution of changes in the balance between DNA methylation and demethylation activities in the nucleus is currently far from clear. Currently, we do not have much information on how various environmental endogenous and exogenous factors influence the balance between the DNA methylation and demethylation activities in the nucleus.

\section{SALT INTAKE AND CHANGES IN RAT AGT PROMOTER DNA METHYLATION STATUS}

Circulating adipose tissue-derived AGT is increased in obese patients with hypertension. ${ }^{14,17,37}$ High-salt intake is associated with obese
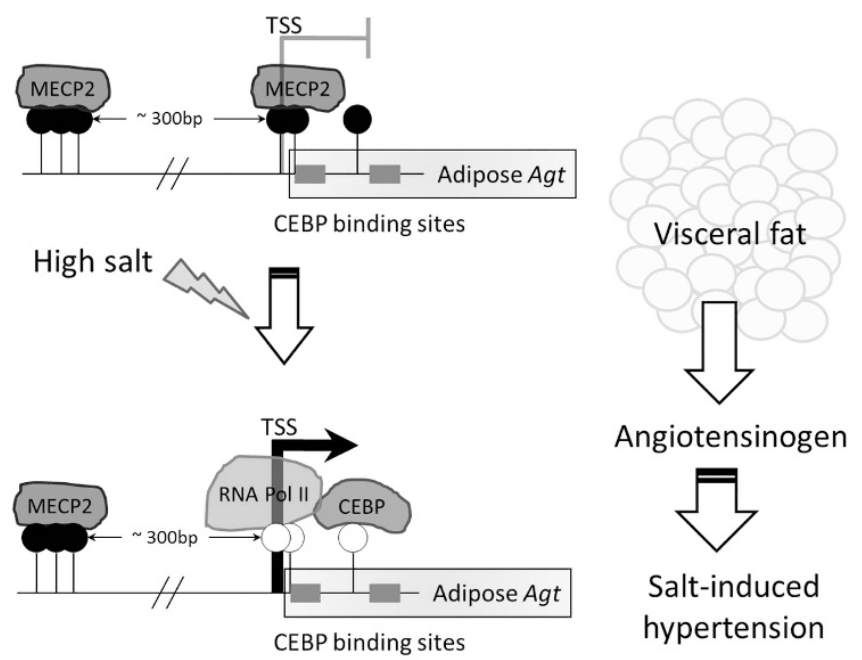

Salt-induced hypertension

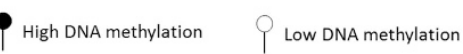

Figure 3 Salt-induced Agt transcription in rat visceral adipose tissue. CEBP CCAAT/enhancer binding protein; TSS, transcription start site. A full color version of this figure is available at the Hypertension Research journal online. human subjects, ${ }^{38}$ suggesting a potential link between high-salt intake and increased adipose AGT in humans. Overall, 12 out of the $13 \mathrm{CpG}$ dinucleotides located within the rat Agt promoter, the first exon and first intron (positions -364 to +207 ) have been analyzed to determine whether high-salt intake increases Agt expression and whether changes in DNA methylation patterns occur in visceral adipose tissue (VAT) from Wistar Kyoto rats.

CEBP has a pivotal role in the transcriptional regulation of the AGT gene in both humans ${ }^{26,34}$ and rats. ${ }^{39}$ Two CEBP-binding sites (CTTGCTCCA, positions +2 to +10 ; CTGGGAA, positions +78 to +84 ) exist in the first exon of the rat Agt gene. High-salt intake increases VAT Agt and demethylates the Agt promoter in rats. DNA demethylation occurs around the TSS and these CEBP-binding sites. ${ }^{23}$

As noted above, DNA demethylation occurs in relaxed chromatin regions where transcription factors interact with their target site (Figure 2b). Using cultured hepatocytes, functional glucocorticoid response elements (GRE I and II) have been identified approximately $100 \mathrm{bp}$ apart from each other in the rat Agt promoter. ${ }^{39}$ The acutephase response element (APRE), which is located between GRE I and II, mediates rat hepatic Agt transcription. ${ }^{39,40}$ However, these cis-acting elements are not involved in salt-inducible Agt transcription. No change in DNA methylation has occurred in the region ranging from CpG1 to CpG4 around the APRE and GRE II, suggesting the lack of interaction of transcription factors with these sites. Collectively, these results suggest that a salt-associated stimulatory signal may recruit CEBP to its binding sites in the first exon, rather than to the APRE, to activate Agt transcription.

Although high-salt intake suppresses the level of circulating RAAS, VAT Agt expression is paradoxically increased in high-salt diet-fed rats. Salt intake can activate sympathetic nerve activity ${ }^{41,42}$ and lead to changes in the adipose tissue gene expression profile. In humans, $\beta$-adrenergic stimulation elevates circulating angiotensin II levels and increases adipose tissue AGT release from obese subjects. ${ }^{43}$ As highsalt intake increases VAT Agt expression in rats, salt-dependent hypertension in humans may be partially dependent on increased VAT AGT expression. A close association exists between low DNA methylation at CEBP-binding sites and increased Agt gene expression in rats (Figure 3). Further research is needed to elucidate whether high-salt intake stimulates VAT AGT in humans.

\section{DIFFERENTIAL EFFECTS OF CORTISOL AND ALDOSTERONE ON HUMAN AGT PROMOTER DNA DEMETHYLATION PATTERNS}

Cortisol and aldosterone exert differential effects through binding and activation of a subfamily of NR3C glucocorticoid receptors (GRs) (NR3C1) and mineralocorticoid receptors (MRs) (NR3C2), respectively. GRs and MRs form either homo- or hetero-dimers, bind to GRE and modulate gene transcription. In our study that compared VAT surrounding cortisol-producing adenoma (Cushing's syndrome, $\mathrm{CS}$ ), aldosterone-producing adenoma (APA) and non-functioning adenoma (NFA), we have drawn a strong conclusion that both cortisol and aldosterone can stimulate VAT AGT transcription, with accompanying AGT promoter DNA demethylation in adult humans. ${ }^{23}$ However, the effect of cortisol on VAT AGT transcription was different from aldosterone in terms of agonist efficacy. Aldosterone, although approximately 1000 times less abundant than cortisol, exerts a significant stimulatory effect on VAT $A G T$ transcription, whereas cortisol does so to a much lesser extent (Figure 4a).

In rodents, glucocorticoids upregulate Agt expression in both the liver ${ }^{44-46}$ and adipose tissues. ${ }^{47,48}$ Glucocorticoids also stimulate AGT transcription, ${ }^{26}$ expression $^{49}$ and AGT secretion ${ }^{50}$ in human 


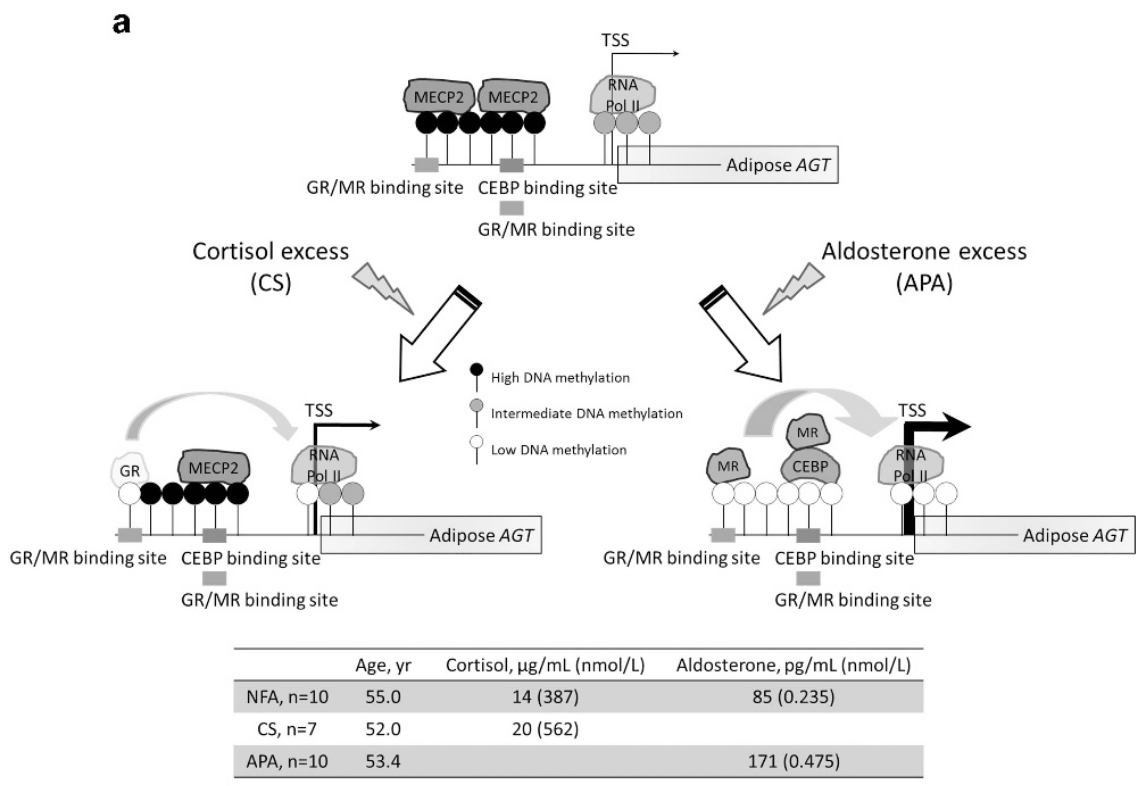

b

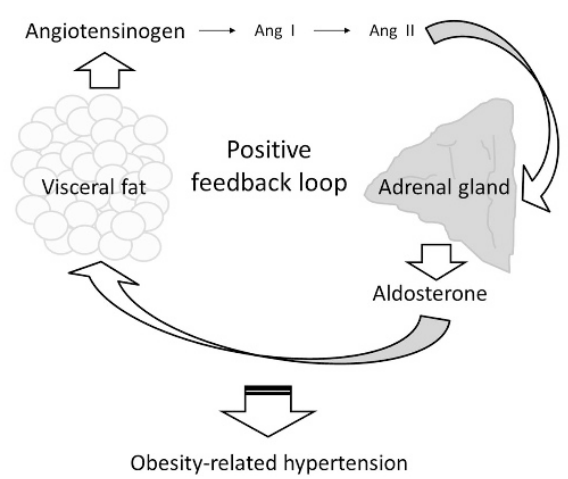

Figure 4 (a) Differential effects of excess cortisol and aldosterone on AGT transcription in visceral adipose tissue. A hypothetical set of interactions between DNA-binding proteins and the AGT promoter is shown. (b) Positive feedback loop of the renin-angiotensin-aldosterone system in human visceral adipose tissue. Ang, angiotensin; APA, aldosterone-producing adenoma; CEBP, CCAAT/enhancer binding protein; CS, Cushing syndrome; GR, glucocorticoid receptor; MR, mineralocorticoid receptor; NFA, non-functioning adenoma; RNA pol II, RNA polymerase II; TSS, transcription start site. A full color version of this figure is available at the Hypertension Research journal online.

hepatocytes. Circulating AGT levels are elevated in CS patients or following glucocorticoid administration. ${ }^{51}$ Whether cortisol stimulates adipose $A G T$ expression in humans remains controversial. Cortisol has no stimulatory effect on $A G T$ expression in primary adipocytes from human mammary adipose tissue. ${ }^{52}$ In our study, however, VAT AGT expression in CS patients tended to be higher than in NFA patients. As mentioned, DNA demethylation occurs in relaxed chromatin regions both where transcription is initiated and where transcription factors actively interact (Figure 2b). Therefore, the low DNA methylation levels observed at CpG12 (positions - 18/-17) and CpG13 (positions $-11 /-10)$ near a TSS clearly indicate that excess cortisol activates VAT AGT transcription in CS patients. Furthermore, low DNA methylation levels at CpG2 (positions -434/-433) and CpG3 (positions - 386/-385) around the distal GREs (positions - 404/ $-400,-397 /-393,-376 /-371)$ strongly suggest that activated GRs are involved in transcriptional activation through their interaction with the distal GREs (Figure 4a). Taken together, these results suggest that cortisol has a weak but definite ability to stimulate VAT AGT transcription in adult humans.

An excess of aldosterone in APA elicits low DNA methylation levels at all CpG dinucleotides from CpG1 (positions -460/-459) to
CpG13 (positions - 11/-10) in the AGT promoter with an accompanying upregulation of VAT AGT expression (Figure 4a). In our study in which we observed dynamic changes in DNA methylation patterns following IL6 stimulation, the first DNA demethylation event occurred around CpG9 (positions -218/-217) in the AGT promoter. ${ }^{23} \mathrm{CpG} 9$ exists in a DNA sequence that functions as both a GRE and a CEBP-binding site (positions - 225/-217) ${ }^{26}$ (Figure 1), implying that the activation of MRs (NR3C2) but not GRs (NR3C1) initiates chromatin remodeling along with CEBP. Members of the NR3C subfamily and many other nuclear receptor superfamily members act cooperatively with other DNA-binding transcription factors. The interaction of their target DNA sequences can integrate the hormonal response to other regulatory pathways. ${ }^{53}$ Indeed, modulation of rat Agt transcription by glucocorticoids and IL1 is synergistic and interdependent. ${ }^{39}$ As is the case with IL6-induced AGT activation, MRs and other transcription factors such as CEBP, STAT3, and HNF1A can bind DNA between CpG1 (positions - 460/-459) and CpG13 (positions -11/-10) of the AGT promoter and might be involved in the transcriptional activation of $A G T$ when there is an excess of aldosterone. ${ }^{27}$ Collectively, these results suggest that activated MRs bind DNA at positions $-225 /-217$ and have a leading role in 
a

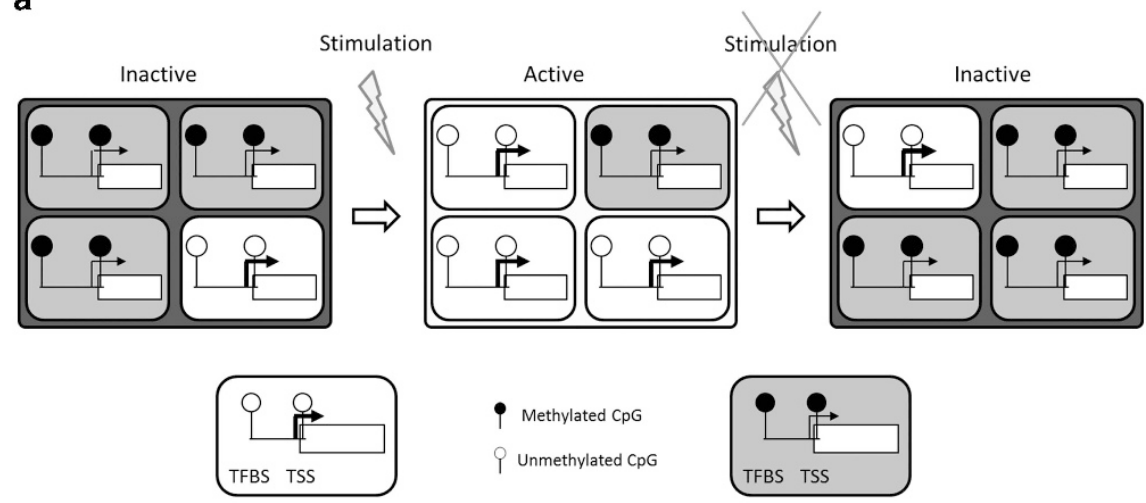

Cells efficiently expressing a target gene

Cells inefficiently expressing a target gene

b

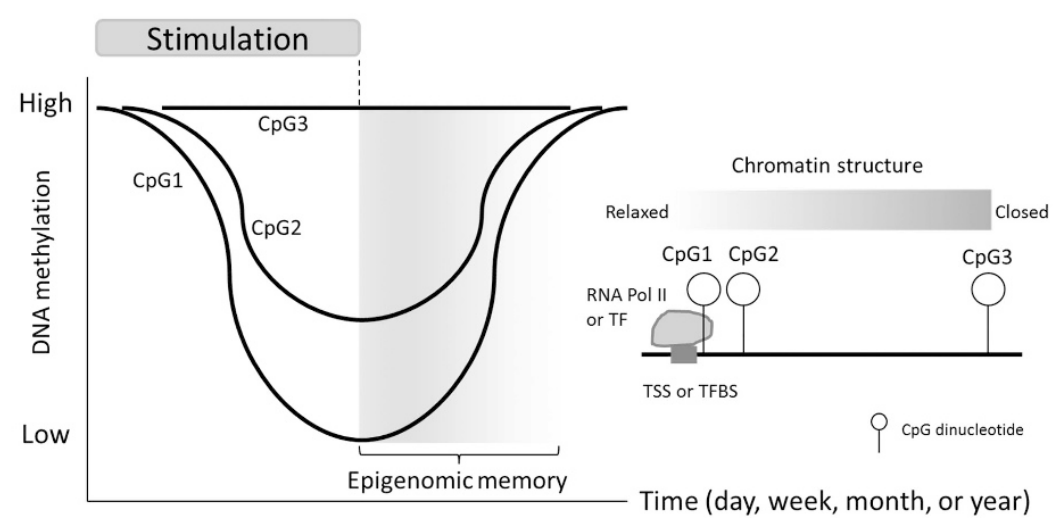

Figure 5 (a) Gene expression phenotype conversion. Stimulatory signals switch the gene expression phenotype from an inactive to an active state within a tissue. Following stimulation, the gene expression phenotype is gradually restored to its former state. (b) Schematic representation of dynamic changes in DNA methylation patterns. Stimulation can induce DNA demethylation. DNA remethylation takes place following stimulus removal. The degree of changes in DNA methylation depends on local chromatin structure. RNA pol II, RNA polymerase II; TF, transcription factor; TFBS, transcription factor-binding site. A full color version of this figure is available at the Hypertension Research journal online.

the transcriptional activation of $A G T$, thereby recruiting other transcription factors (Figure 4a).

Aldosterone upregulates Agt expression in Reuber H35 (H4IIE) rat hepatoma cells. ${ }^{44}$ Aldosterone stimulates AGT secretion in Ob1771 mouse adipocytes. ${ }^{47}$ However, the dose of aldosterone required to elicit these responses is even greater than glucocorticoids. Moreover, the fact that glucocorticoid antagonist administration reverses these responses to aldosterone suggests that these responses are mediated through the interaction with GRs, not MRs. ${ }^{44,47}$ Thus these stimulatory effects of aldosterone occur only in the pharmacological range and are not considered to be physiologically important. By contrast, aldosterone exerts an extremely strong effect on VAT AGT transcription in humans. CS and APA are each diagnosed in the early stages at present. The mean values of circulating cortisol and aldosterone levels are at approximately the upper limits of the normal range in CS and APA (Figure 4a). Therefore, the effects of cortisol and aldosterone on VAT AGT transcription are of physiological importance and shed light on species differences between humans and rodents regarding the action of corticosteroids.

Controversy exists as to which GRE interacts with GRs in the AGT promoter. In an early study, overexpressed GRs interacted with the AGT promoter at positions $-225 /-217$ in human hepatoma Hep3B cells. ${ }^{26}$ However, GRs appear to interact at distal GREs (positions $-404 /-400,-397 /-393,-376 /-371)$ but not at positions $-225 /$ -217 in the human VAT in our study ${ }^{23}$ (Figure $4 a$ ). GRs affect VAT
AGT transcription via distal GREs under physiological conditions. This discrepancy in the GR-binding sites in the AGT promoter is most likely due to a difference in either cell types or experimental conditions.

The RAAS is a system of major importance in control of fluid and electrolyte homeostasis. This positive feedback effect of aldosterone allows for efficient fluid retention, which is especially effective in the context of dehydration in humans. In addition, this effect may contribute to the development of hypertension in cases of obesity as well as in cases of CS and APA despite decreased circulating renin levels in these pathologies (Figure $4 \mathrm{~b}$ ).

High DNA methylation around a TSS is associated with the absence of RNA polymerase II. Low DNA methylation around a TSS is associated with the presence of either active (high transcription levels) or stalled (low transcription levels) RNA polymerase II. ${ }^{54}$ DNA methylation patterns from CpG1 to CpG9 of the VAT AGT promoter in NFA are high, whereas those from CpG10 to CpG17 around the TSS in NFA are not $^{23}$ (Figures 1 and $4 \mathrm{a}$ ). The combination of high DNA methylation in the promoter region and intermediate DNA methylation around the TSS suggests that RNA polymerase II is stalled in the VAT AGT gene in NFA. As excessive salt in contemporary diets reduces circulating RAAS levels, ${ }^{55}$ the DNA methylation patterns of VAT AGT in NFA reflects the reduced levels of circulating RAAS in contemporary humans and the readiness to produce AGT. Collectively, these results suggest that VAT is a major site of AGT production 
in humans. In contrast to rodents, aldosterone efficiently stimulates VAT AGT production in humans.

\section{VARIOUS STIMULI EXPERIENCED IN DAILY LIFE INFLUENCE DNA METHYLATION PATTERNS}

Using the AGT gene as a typical example, we demonstrate in vitro and in vivo dynamic changes in DNA methylation in association with stimulatory signals. Stimulatory signals switch the gene expression phenotype within a tissue from an inactive to an active state. (Figure 5a). The aldosterone synthase CYP11B2 gene demonstrates similar patterns of dynamic DNA methylation changes in association with stimulatory signals in vitro and in vivo (unpublished observations). The dynamics of locus-specific DNA demethylation upon transcriptional activation can be observed in cultured cells ${ }^{23,29,33,56}$ and lymphocytes. ${ }^{30,57}$ DNA demethylation is observed within dozens of minutes to days of transcriptional activation and reaches a maximum level in hours to years. Thus sustained stimulation keeps DNA methylation patterns hypomethylated over days or years (Figure 5b).

By contrast, what happens to DNA methylation patterns when transcriptional activation is no longer stimulated receives less attention, and whether DNA remethylation occurs at that point remains unclear. There is an example where DNA remethylation does not occur; glucocorticoid-induced DNA demethylation at a distal enhancer element of the rat Tat gene is maintained for at least 3 months following glucocorticoid withdrawal. ${ }^{29}$ However, in our study, DNA remethylation occurred in both the AGT and CYP11B2 genes. We propose a conceptual model whereby DNA remethylation gradually increases within the promoter and around the TSS following the removal of a stimulus (Figure 5b). The data presently available on changes in DNA methylation patterns following stimuli removal are not abundant and are far from clear.

In contrast to rapid histone modifications, DNA methylation patterns slowly cycle back and forth between high and low DNA methylation following stimulation. Furthermore, DNA demethylation occurs in relaxed chromatin regions. Based on our observations, the distance from a transcription factor-binding site or a TSS determines the degree of chromatin relaxation in both the AGT and CYP11B2 genes. Thus the degree of changes in DNA methylation patterns depends on the distance from a transcription factor-binding site or a TSS (Figure 5b). DNA methylation patterns act as memory to maintain gene expression responsiveness to additional signals. DNA methylation patterns have a profound effect on gene transcription and thus affect constitution in a tremendous way. A wide variety of stimuli in daily life continue to slowly and dynamically change DNA methylation patterns throughout life.

\section{CONCLUSION}

Over the past few decades, tremendous efforts have been made to elucidate the plasticity of DNA methylation patterns with a successful outcome. Over many years, DNA methylation patterns have been considered as being stably maintained. However, various endogenous and exogenous environmental factors can dynamically change DNA methylation patterns. Genetic and environmental factors determine human health. Thus wise choices in terms of environmental factor exposure will improve health through dynamic changes in DNA methylation patterns.

In contrast to DNA demethylation, DNA remethylation is far from being well understood. We need to clarify where and how DNA remethylation takes place following stimulus removal. Epigenetic mapping of changes in patterns of DNA demethylation and remethylation in response to various environmental factors will lead to health promotion and disease prevention based on epigenetic control exerted by the individual.

\section{CONFLICT OF INTEREST}

The authors declare no conflict of interest.

\section{ACKNOWLEDGEMENTS}

This study was supported by the Japan Society for Takeda Science Foundation (to M Demura).

1 Bogdarina I, Welham S, King PJ, Burns SP, Clark AJ. Epigenetic modification of the renin-angiotensin system in the fetal programming of hypertension. Circ Res 2007, 100: 520-526.

2 Arai Y, Ohgane J, Yagi S, Ito R, Iwasaki Y, Saito K, Akutsu K, Takatori S, Ishii R, Hayashi R, Izumi S, Sugino N, Kondo F, Horie M, Nakazawa H, Makino T, Shiota K. Epigenetic assessment of environmental chemicals detected in maternal peripheral and cord blood samples. J Repro Dev 2011; 57: 507-517.

3 Nakajima T, Yamashita S, Maekita T, Niwa T, Nakazawa K, Ushijima T. The presence of a methylation fingerprint of Helicobacter pylori infection in human gastric mucosae. $J$ Int Cancer 2009; 124: 905-910.

4 Oka D, Yamashita S, Tomioka T, Nakanishi Y, Kato H, Kaminishi M, Ushijima T. The presence of aberrant DNA methylation in noncancerous esophageal mucosae in association with smoking history: a target for risk diagnosis and prevention of esophageal cancers. Cancer 2009; 115: 3412-3426.

5 Zhang Y, Yang R, Burwinkel B, Breitling LP, Brenner H. F2RL3 methylation as a biomarker of current and lifetime smoking exposures. Environ Health Perspect 2014 122: 131-137.

6 Ronn T, Volkov P, Davegardh C, Dayeh T, Hall E, Olsson AH, Nilsson E, Tornberg A, Dekker Nitert M, Eriksson KF, Jones HA, Groop L, Ling C. A six months exercise intervention influences the genome-wide DNA methylation pattern in human adipose tissue. PLoS Genet 2013; 9: e1003572.

7 Miller CA, Gavin CF, White JA, Parrish RR, Honasoge A, Yancey CR, Rivera IM Rubio MD, Rumbaugh G, Sweatt JD. Cortical DNA methylation maintains remote memory. Nat Neurosci 2010; 13: 664-666.

8 Bind MA, Zanobetti A, Gasparrini A, Peters A, Coull B, Baccarelli A, Tarantini L, Koutrakis $P$, Vokonas $P$, Schwartz J. Effects of temperature and relative humidity on DNA methylation. Epidemiology 2014; 25: 561-569.

9 Petersen AK, Zeilinger S, Kastenmuller G, Romisch-Margl W, Brugger M, Peters A Meisinger C, Strauch K, Hengstenberg C, Pagel P, Huber F, Mohney RP, Grallert H Illig T, Adamski J, Waldenberger M, Gieger C, Suhre K. Epigenetics meets metabolomics: an epigenome-wide association study with blood serum metabolic traits. Hum Mol Genet 2014; 23: 534-545.

10 Campbell DJ. Tissue renin-angiotensin system: sites of angiotensin formation. J Cardiovasc Pharmacol 1987; 10: S1-S8.

11 Massiera F, Bloch-Faure M, Ceiler D, Murakami K, Fukamizu A, Gasc JM, Quignard Boulange A, Negrel R, Ailhaud G, Seydoux J, Meneton P, Teboul M. Adipose angiotensinogen is involved in adipose tissue growth and blood pressure regulation. FASEB J 2001; 15: 2727-2729.

12 Masuzaki H, Yamamoto H, Kenyon CJ, Elmquist JK, Morton NM, Paterson JM Shinyama H, Sharp MG, Fleming S, Mullins JJ, Seckl JR, Flier JS. Transgenic amplification of glucocorticoid action in adipose tissue causes high blood pressure in mice. J Clin Invest 2003; 112: 83-90.

13 Rahmouni K, Mark AL, Haynes WG, Sigmund CD. Adipose depot-specific modulation of angiotensinogen gene expression in diet-induced obesity. Am J Physiol Endocrinol Metab 2004; 286: E891-E895.

14 Yasue S, Masuzaki H, Okada S, Ishii T, Kozuka C, Tanaka T, Fujikura J, Ebihara K, Hosoda K, Katsurada A, Ohashi N, Urushihara M, Kobori H, Morimoto N, Kawazoe T, Naitoh M, Okada M, Sakaue H, Suzuki S, Nakao K. Adipose tissue-specific regulation of angiotensinogen in obese humans and mice: impact of nutritional status and adipocyte hypertrophy. Am J Hypertens 2010; 23: 425-431.

15 Yiannikouris F, Gupte M, Putnam K, Thatcher S, Charnigo R, Rateri DL, Daugherty A, Cassis LA. Adipocyte deficiency of angiotensinogen prevents obesity-induced hypertension in male mice. Hypertension 2012; 60: 1524-1530.

16 Yiannikouris F, Karounos M, Charnigo R, English VL, Rateri DL, Daugherty A, Cassis LA Adipocyte-specific deficiency of angiotensinogen decreases plasma angiotensinogen concentration and systolic blood pressure in mice. Am J Physiol Regul Integr Comp Physiol 2012; 302: R244-R251.

17 Gur M, Elbasan Z, Yildiray Sahin D, Yildiz Koyunsever N, Seker T, Ozaltun B, Cayli M, Kocyigit A. DNA damage and oxidative status in newly diagnosed, untreated, dipper and non-dipper hypertensive patients. Hypertens Res 2013; 36: 166-171.

18 Qi Y, Zhao H, Wang Y, Wang Y, Lu C, Xiao Y, Cao J, Jia N, Wang B, Niu W. Replication of the top 10 most significant polymorphisms from a large blood pressure genome-wide association study of northeastern Han Chinese East Asians. Hypertens Res 2014; 37: $134-138$. 
19 Hong YC, Kim H, Lim YH, Yoon HJ, Kwon YM, Park M. Identification of RAS genotypes that modulate blood pressure change by outdoor temperature. Hypertens Res 2013; 36: $540-545$

20 Olearczyk J, Gao S, Eybye M, Yendluri S, Andrews L, Bartz S, Cully D, Tadin-Strapps M. Targeting of hepatic angiotensinogen using chemically modified siRNAs results in significant and sustained blood pressure lowering in a rat model of hypertension. Hypertens Res 2014; 37: 405-412.

21 Ballestar E, Wolffe AP. Methyl-CpG-binding proteins. Targeting specific gene repression. Eur J Biochem 2001; 268: 1-6.

22 Wang F, Demura M, Cheng Y, Zhu A, Karashima S, Yoneda T, Demura Y, Maeda Y, Namiki M, Ono K, Nakamura Y, Sasano H, Akagi T, Yamagishi M, Saijoh K, Takeda Y. Dynamic CCAAT/enhancer binding protein-associated changes of DNA methylation in the angiotensinogen gene. Hypertension 2014; 63: 281-288.

23 Dickson ME, Tian X, Liu X, Davis DR, Sigmund CD. Upstream stimulatory factor is required for human angiotensinogen expression and differential regulation by the $\mathrm{A}-2 \mathrm{CC}$ polymorphism. Circ Res 2008; 103: 940-947.

24 Zhao YY, Zhou J, Narayanan CS, Cui Y, Kumar A. Role of C/A polymorphism at -20 on the expression of human angiotensinogen gene. Hypertension 1999; 33: 108-115.

25 Jain S, Li Y, Patil S, Kumar A. A single-nucleotide polymorphism in human angiotensinogen gene is associated with essential hypertension and affects glucocorticoid induced promoter activity. J Mol Med (Berl) 2005; 83: 121-131.

26 Jain S, Li Y, Patil S, Kumar A. HNF-1alpha plays an important role in IL-6-induced expression of the human angiotensinogen gene. Am J Physiol Cell Physiol 2007; 293: C401-C410.

27 Yanai K, Hirota K, Taniguchi-Yanai K, Shigematsu Y, Shimamoto Y, Saito T, Chowdhury S, Takiguchi M, Arakawa M, Nibu Y, Sugiyama F, Yagami K, Fukamizu A. Regulated expression of human angiotensinogen gene by hepatocyte nuclear factor 4 and chicken ovalbumin upstream promoter-transcription factor. J Biol Chem 1999; 274: 34605-34612.

28 Thomassin H, Flavin M, Espinas ML, Grange T. Glucocorticoid-induced DNA demethylation and gene memory during development. EMBO J 2001; 20: 1974-1983.

29 Bruniquel D, Schwartz RH. Selective, stable demethylation of the interleukin-2 gene enhances transcription by an active process. Nat Immunol 2003; 4: 235-240.

30 Kangaspeska S, Stride B, Metivier R, Polycarpou-Schwarz M, Ibberson D, Carmouche RP, Benes V, Gannon F, Reid G. Transient cyclical methylation of promoter DNA. Nature 2008; 452: 112-115.

31 Metivier R, Gallais R, Tiffoche C, Le Peron C, Jurkowska RZ, Carmouche RP, Ibberson D, Barath P, Demay F, Reid G, Benes V, Jeltsch A, Gannon F, Salbert G. Cyclical DNA methylation of a transcriptionally active promoter. Nature 2008; 452 : 45-50.

32 Thillainadesan G, Chitilian JM, Isovic M, Ablack JN, Mymryk JS, Tini M, Torchia J. TGF-beta-dependent active demethylation and expression of the p15ink4b tumor suppressor are impaired by the ZNF217/CoREST complex. Mol Cell 2012; 46: 636-649.

33 Jain S, Tang X, Narayanan CS, Agarwal Y, Peterson SM, Brown CD, Ott J, Kumar A Angiotensinogen gene polymorphism at -217 affects basal promoter activity and is associated with hypertension in African-Americans. J Biol Chem 2002; 277: 36889-36896.

34 Guo X, Wang L, Li J, Ding Z, Xiao J, Yin X, He S, Shi P, Dong L, Li G, Tian C, Wang J, Cong $Y, X u Y$. Structural insight into autoinhibition and histone H3-induced activation of DNMT3A. Nature 2014; 517: 640-644.

35 Sherman CT, Brasier AR. Role of signal transducers and activators of transcription 1 and -3 in inducible regulation of the human angiotensinogen gene by interleukin-6. Mol Endocrinol 2001; 15: 441-457.

36 Umemura S, Nyui N, Tamura K, Hibi K, Yamaguchi S, Nakamaru M, Ishigami T, Yabana M, Kihara M, Inoue S, Ishii M. Plasma angiotensinogen concentrations in obese patients. Am J Hypertens 1997; 10: 629-633.
37 Van Harmelen V, Ariapart P, Hoffstedt J, Lundkvist I, Bringman S, Arner P. Increased adipose angiotensinogen gene expression in human obesity. Obes Res 2000; 8 : 337-341.

38 Baudrand R, Campino C, Carvajal CA, Olivieri O, Guidi G, Faccini G, Vohringer PA, Cerda J, Owen G, Kalergis AM, Fardella CE. High sodium intake is associated with increased glucocorticoid production, insulin resistance and metabolic syndrome. Clin Endocrinol (Oxf) 2013; 80: 677-684.

39 Brasier AR, Ron D, Tate JE, Habener JF. Synergistic enhansons located within an acute phase responsive enhancer modulate glucocorticoid induction of angiotensinogen gene transcription. Mol Endocrinol 1990; 4: 1921-1933.

40 Zhao YY, Qasba P, Siddiqui MA, Kumar A. Multiple CCAAT binding proteins regulate the expression of the angiotensinogen gene. Cell Mol Biol Res 1993; 39: 727-737.

41 Adams JM, Madden CJ, Sved AF, Stocker SD. Increased dietary salt enhances sympathoexcitatory and sympathoinhibitory responses from the rostral ventrolateral medulla. Hypertension 2007; 50: 354-359.

42 Simmonds SS, Lay J, Stocker SD. Dietary salt intake exaggerates sympathetic reflexes and increases blood pressure variability in normotensive rats. Hypertension 2014; 64: 583-589.

43 Goossens GH, Jocken JW, Blaak EE, Schiffers PM, Saris WH, van Baak MA. Endocrine role of the renin-angiotensin system in human adipose tissue and muscle: effect of betaadrenergic stimulation. Hypertension 2007; 49: 542-547.

44 Chang E, Perlman AJ. Multiple hormones regulate angiotensinogen messenger ribonucleic acid levels in a rat hepatoma cell line. Endocrinology 1987; 121: 513-519.

45 Ben-Ari ET, Garrison JC. Regulation of angiotensinogen mRNA accumulation in rat hepatocytes.Am J Physiol 1988; 255: E70-E79.

46 Ben-Ari ET, Lynch KR, Garrison JC. Glucocorticoids induce the accumulation of novel angiotensinogen gene transcripts. J Biol Chem 1989; 264: 13074-13079.

47 Aubert J, Darimont C, Safonova I, Ailhaud G, Negrel R. Regulation by glucocorticoids of angiotensinogen gene expression and secretion in adipose cells. Biochem J 1997; 328: 701-706.

48 Turban S, Hainault I, Truccolo J, Andre J, Ferre P, Quignard-Boulange A, Guerre-Millo M. Specific increase in leptin production in obese (falfa) rat adipose cells. Biochem J 2002; 362: 113-118.

49 Kunapuli SP, Fuller GM, Kumar A. Regulation of angiotensinogen gene expression in a human hepatoma cell line. Life Sci 1987; 41: 2397-2401.

50 Campbell DJ, Bouhnik J, Coezy E, Menard J, Corvol P. Characterization of precursor and secreted forms of human angiotensinogen. J Clin Invest 1985; 75: 1880-1893.

51 Krakoff LR. Measurement of plasma renin substrate by radioimmunoassay of angiotensin. I. Concentration in syndromes associated with steroid excess. J Clin Endocrinol Metab 1973; 37: 110-117.

52 Gorzelniak K, Engeli S, Janke J, Luft FC, Sharma AM. Hormonal regulation of the human adipose-tissue renin-angiotensin system: relationship to obesity and hypertension. J Hypertens 2002; 20: 965-973.

53 Schule R, Muller M, Kaltschmidt C, Renkawitz R. Many transcription factors interact synergistically with steroid receptors. Science 1988; 242: 1418-1420.

54 Takeshima H, Yamashita S, Shimazu T, Niwa T, Ushijima T. The presence of RNA polymerase II, active or stalled, predicts epigenetic fate of promoter $\mathrm{CpG}$ islands. Genome Res 2009; 19: 1974-1982.

55 Oliver WJ, Cohen EL, Neel JV. Blood pressure, sodium intake, and sodium related hormones in the Yanomamo Indians, a "no-salt" culture. Circulation 1975; 52: $146-151$.

56 Qiang M, Denny A, Chen J, Ticku MK, Yan B, Henderson G. The site specific demethylation in the $5^{\prime}$-regulatory area of NMDA receptor 2B subunit gene associated with CIE-induced up-regulation of transcription. PLoS One 2010; 5: e8798.

$57 \mathrm{Li} \mathrm{Y,} \mathrm{Chen} \mathrm{G,} \mathrm{Ma} \mathrm{L,} \mathrm{Ohms} \mathrm{SJ,} \mathrm{Sun} \mathrm{C,} \mathrm{Shannon} \mathrm{MF,} \mathrm{Fan} \mathrm{JY.} \mathrm{Plasticity} \mathrm{of}$ DNA methylation in mouse T cell activation and differentiation. BMC Mol Biol 2012; 13: 16 . 